\title{
Environmental and human health issues related to long-term contamination by chlordecone in the French Caribbean
}

\author{
Pierre Benoit ${ }^{1}$ - Jean Pierre Cravedi ${ }^{2}$ Jean-Claude Desenclos ${ }^{3} \cdot$ Christophe Mouvet $^{4} \cdot$ Guido Rychen $^{5}$. \\ Michel Samson ${ }^{6}$
}

Published online: 16 June 2020

(C) Springer-Verlag GmbH Germany, part of Springer Nature 2020

Chlordecone is an organochlorine insecticide extensively used in the French Caribbean (FC), Guadeloupe and Martinique, from 1972 to 1993. This pesticide, which was applied on banana plantations to control banana weevil, undergoes an extremely slow degradation in the environment and is still present in soils where it was applied. It was only in 1999 that French health and environmental authorities became aware of the extent of the pollution due to chlordecone. In addition to soils, it was detected in rivers and groundwaters as well as in coastal ecosystems, and was found to contaminate the terrestrial and aquatic food chains. From that date, the consequences of long-term environmental contamination by chlordecone on human and ecosystem health were considered of major concern. Chlordecone toxicological studies performed in rodents demonstrated evidence of kidney lesions, hepatotoxicity, neurotoxicity, reprotoxicity, developmental toxicity, and carcinogenicity. Chlordecone is also an endocrine-disrupting chemical due to its estrogenic properties both in vitro and in vivo. Epidemiological studies have recently shown that the exposure to chlordecone is associated with the occurrence of adverse health events including prostate cancer.

Responsibility Editor: Philippe Garrigues

Pierre Benoit

pierre.benoit@inrae.fr

1 UMR ECOSYS, INRAE, AgroParisTech, Université Paris-Saclay, 78850 Thiverval-Grignon, France

2 UMR Toxalim, INRAE, ENVT, INPT Purpan, Université de Toulouse, 31027 Toulouse, France

3 Santé publique France, 94415 Saint-Maurice, France

4 BRGM - DEPA/CEL, 45060 Orléans, France

5 ENSAIA, URAFPA, ENSAIA, INRAE, Université de Lorraine, 54505 Vandoeuvre Les Nancy, France

6 Inserm, EHESP, Irset (Institut de recherche en santé, environnement et travail), Univ Rennes, UMR_S, 1085 Rennes, France
Since early 2000s, surveys conducted in the French Caribbean have confirmed that in contaminated areas, soils, rivers, spring and ground waters, aquatic biota, and crops were polluted by chlordecone. This situation became a major concern for FC citizens and for French health authorities, giving rise, among other initiatives, to several research programs encouraged and founded in the frame of the PNAC (national action plan chlordecone) supported by the French Government which started in 2008 through 3 successive plans (PNAC 1 2008-2010, PNAC 2 2011-2013, and PNAC 3 2014-2020). These programs aimed at filling gaps and providing data on the occurrence of chlordecone in environmental matrices, on its carry over and transfer in the food chain, on human exposure as well as its social factors, and on the (eco-)toxicological and health effects of chlordecone.

A scientific conference on chlordecone followed by public restitution days were held in Martinique and in Guadeloupe from October 16 to 19, 2018. During the conference, which gathered more than 200 scientists and experts, recent advances in different scientific fields of research dealing with environmental issues, plant and animal production sectors, human health concerns, humanities, and social sciences were presented. The conference aimed at fostering interactions and synergies between scientific disciplines around the "one Health" concept which promotes integrated and systemic approaches of human and ecosystem health. The goal was to present and discuss possible solutions to reduce the contamination of ecosystems and human populations' exposure.

Improving the knowledge of chlordecone contamination in soils and its migration to waterbodies remains necessary before promoting measures to reduce its dispersion at the catchment scale. Field observations, experimental studies, and modelling approaches addressing the dispersion of chlordecone have been conducted in instrumented sites dedicated to pesticides in both Guadeloupe and Martinique (OPALE observatory). These catchments are representative of contaminated areas with a significant proportion of land 
occupied by formerly treated banana crops. Processes regulating the interactions between the soil and water fluxes have to be thoroughly understood at the plot and catchment scale in order to precise the seasonal dynamics of chlordecone emissions to river and ground waters, the predominance of soluble versus suspended particles in these fluxes in relation to rainfall intensity, soil types, landscape position, land use, and cropping practices.

Ecotoxicological impacts of chlordecone concern terrestrial, river, coastal, and marine ecosystems. Bioaccumulation of chlordecone in the food chain, via biomagnification processes, is evidenced for most aquatic organisms. Improving the aquatic ecosystem exposure measurements remains a challenge and standardized and integrated protocols are needed for in situ monitoring of chlordecone and other pesticides in these ecosystems. Integrating new results at different levels of organization of the food web is critical to address the difficult question of long-term effects of chlordecone even at low concentrations in waterbodies. It is therefore necessary to rely on new tools and methods, e.g., sensors, biomarkers, -omics, and analytical platforms, dedicated to ecotoxicological approaches, predictive toxicology, and epidemiological studies.

Decontaminating soils remains a real challenge knowing the very low degradability of chlordecone and the large areas impacted. Different remediation strategies have been developed at different scales. The process based on strongly reducing conditions achieved through addition of zero-valent iron has proven its effectiveness for a nitisol in the field conditions of an actual banana plantation. Enhanced microbial biodegradation remains presently limited to anaerobic laboratory conditions. Other strategies may rely on the use of plant and phytoextraction processes. Once tested in laboratory conditions, the different strategies have to be tested in situ with the different soil types present in the French Caribbean since various processes, e.g., different diffusion and aging of chlordecone in the soil matrix according to the soil type, influence the effectiveness of remediation. Conversely, the enhancement of sequestration processes by addition of exogeneous organic matter in soils represents a way to reduce the transfer from soil to water and crops.

It is well recognized that the contamination process of agricultural products by chlordecone is related to the transfer to the plant of the contaminant present in soil, to the bioaccumulation in animal tissues of chlordecone present in surrounding environment (e.g., bioconcentration in aquatic species), or by the intake of contaminated soil or feed by farm animals. Indeed, for some species, involuntary ingestion of contaminated soil is a very significant route of contamination. The sources of contamination and the toxicokinetic properties of chlordecone in the main target species should therefore be determined in order to recommend breeding practices that can limit the contamination of tissues intended for human consumption. A reduction of chlordecone uptake can be achieved through the use of sequestering agents added to the soil or incorporated into feedstuffs (activated carbons, biochars). If toxicokinetic studies are useful to better understand the contamination process, they may also help to define adequate decontamination strategies, i.e., periods of decontamination of animals compatible with breeding practices.

In humans, exposure via food may vary considerably, depending on the origin of the food. It is therefore essential to have through appropriate and repeated population survey accurate data on the levels of contamination of different commodities, but also to identify the foods and supply chains that contribute the most to exposure. The biomonitoring of the population is another way of assessing the exposure. It allows not only to know the range and median levels of chlordecone in blood in the West Indian population but also to assess the decline of its concentration in blood over time and therefore the effectiveness of the public policies and interventions implemented in the French Caribbean.

Hazard identification and human health effects resulting from the exposure to chlordecone are a subject of important research efforts. Not all of the toxicological effects of chlordecone are known yet, and this may warrant further investigations on the mechanisms of action of this pollutant. Thus, experiments of cell biology or on animal models can be helpful. Further epidemiological investigation, based on large-cohort studies, is also required to find out more on the links between exposure to chlordecone and health outcomes. This include follow-up from conception until death, including pregnancy and child development outcomes, the assessment of the impact on risk of chronic diseases, and cancer, the contribution of occupational exposure ....

This special issue on chlordecone will provide state-of-the art information on occurrence, fate and toxicity of this bioaccumulative, and persistent organochlorine insecticide in the Caribbean environment, as well as on human exposure and health effects associated with its presence in the food chain. Studies providing specific solutions in the field of remediation and decontamination strategies are also included in this volume. 


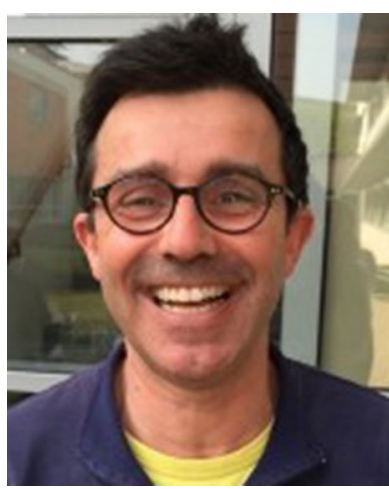

Pierre Benoit, $\mathrm{PhD}$, is a soil scientist and director of research at the French National Research Institute for Agriculture, Food, and Environment (INRAE) working at Joint Research Unit INRAE/AgroParisTech ECOSYS in Thiverval-Grignon. His research interests concern soil science and the coupling of biological and physico-chemical processes involved in the fate and transport of pesticides and other organic contaminants in soil and water. Applications concern the assessment of several management and cropping practices such as organic waste recycling in agricultural soils, soil tillage practices, cover crop introduction, ecological infrastructures such as grassed buffer strips and wetlands, and their impacts on the fate and transport of pesticides and other organic contaminants.

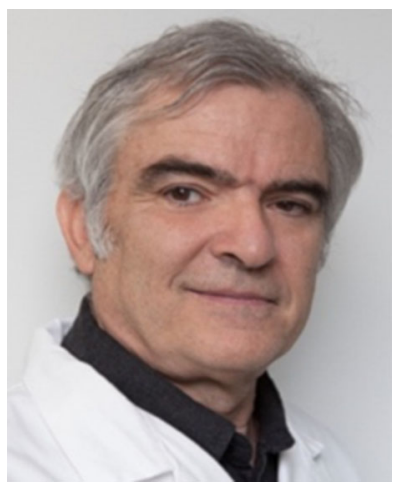

Jean Pierre Cravedi, $\mathrm{PhD}$, is a toxicologist and is a director of research at the French National Research Institute for Agriculture, Food, and Environment (INRAE) at Toulouse. He was until 2019 deputy head of the human nutrition and consumer behavior division, in which he was in charge of food safety scientific programs. He published more than 350 articles and reports in scientific journals, most of them being in the field of food safety, environment, and health. In the last 10 years, he coordinated 3 national or international projects and contributed to 11 research programs. He is currently a member of several working groups at the European Food Safety Authority (EFSA), and the French Agency for Food, Environmental, and Occupational Health and Safety (ANSES).

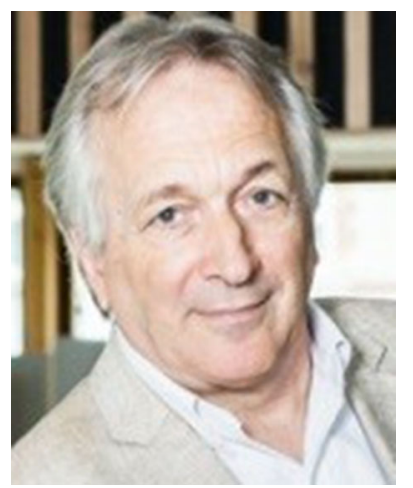

Jean-Claude Desenclos, MD, $\mathrm{PhD}$, moved to public health in 1988 after several years of medical general practice and international humanitarian involvement through Médecins Sans Frontières. After working for 3 years at the US $\mathrm{CDC}$ as a medical epidemiologist, he joined the newly created French National Surveillance Institute (Institut de Veille Sanitaire [InVS]) in 1993. He was the head of the InVS Department of Infectious Diseases for 12 years and became the Scientific Director of InVS in 2008. He then became the scientific director, deputy to the general director at the creation of the new French public health agency (Santé Publique France) in 2016. Dr. Desenclos is the author or co-author of 210 international scientific publications and editor of a French textbook in epidemiology. He is affiliated with the Paris Doctoral School of Public Health where he supervises $\mathrm{PhD}$ students. He participates to numerous scientific committee and advisory boards in France and in Europe. He is an associate editor to the "European Journal of Epidemiology" and the French journal "Santé Publique." Dr. Desenclos currently serves as Secretary General of the International Association of National Public Health Institutes (IANPHI: http://www. ianphi.org/).

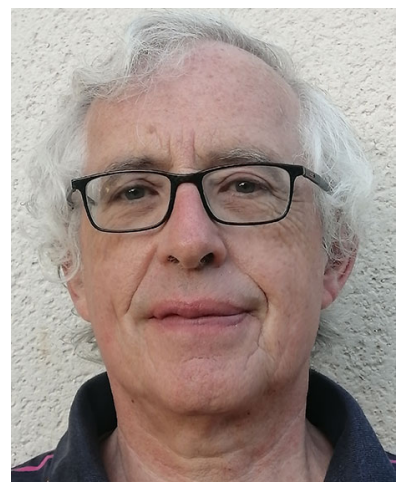

Christophe Mouvet, $\mathrm{PhD}$, is a senior scientist at the Bureau de Recherches Géologiques et Minières (Brgm, the French geological survey). His main research activities are related to the fate of micropollutants, mainly pesticides, and their degradation products from the soil surface to and in groundwaters. He combines laboratory studies with field work, both at various scales, with a strong interest in the analytical issues. For the last 10 years, he has led the Brgm research team on the remediation of soils contaminated by chlordecone, with a focus on the process of In Situ Chemical Reduction (ISCR). Starting from a proof of concept in laboratory mesocosms, ISCR has been validated at plot scale in actual field conditions. He has also coordinated studies on the genotoxicity, mutagenicity, and proangiogenic properties of several chlordecone transformation products formed by ISCR.

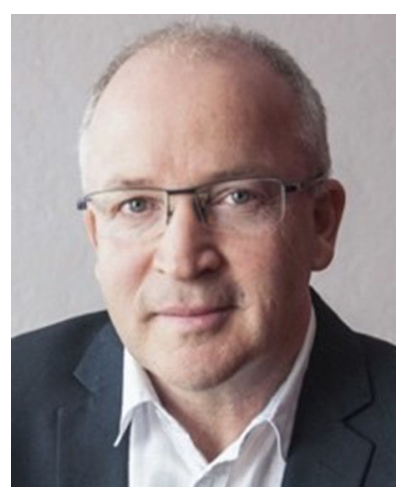

Guido Rychen, PhD, is a Professor in Animal Sciences at the University de Lorraine-Ecole Nationale Supérieure d'Agronomie et des Industries Alimentaires. For 11 years, he managed the INRAE-UL research unit "Unité de recherches Animal et Fonctionnalités des Produits Animaux." His main research area is related to organic pollutants transfer in the food chain. Currently, he is the coordinator of the national INSSICCA project which aims at providing new strategies to secure livestock production systems in chlordeconecontaminated areas (www.inssicca.fr). Since 2003, he is also involved in the safety assessment of feed products and additives at the European Food Safety Authority (EFSA), and was the chair of the FEEDAP panel from 2015 to 2018 . 


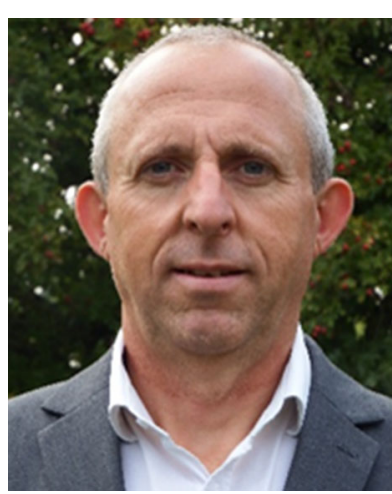

Michel Samson has got his $\mathrm{PhD}$ in 1993 at University of Paris XI (France). He studied as postdoctoral scientist at Université Libre de Bruxelles (Brussels, Belgium) supported by prestigious fellowships (EMBO, European Community, etc.). He passed 2 years as visiting scientist at Genentech (CA, USA). He is now a team leader and director of research of Inserm at University of Rennes (France). He is a director of Institut de Recherche en Santé, Environnement et Travail (Irset; https://www.irset.org/) -UMR 1085 Inserm. He is also a member of several national and international councils: member of Scientific Council of Inserm (20172021), member of Administrative Council of EHESP (National school of Public health) (2018-present), member of Administrative Council of AFEF (French society of Hepatology) (2018-2021), member of SAB of RISUQ (Réseau Intersectoriel de recherche en Santé de l'Université du Québec, Canada) (2019-present). He studies the inflammation, cell death, and the impact of environmental factors in liver pathologies. He has published more than 100 papers in reputed journals (Nature, Cell, J Exp Med, Hepatology, J Hepatol., etc.), with already more than 9400 citations and Hindex 40 . 